UDK: $336.77(497.11)$

DOI: $10.1515 / j c b t p-2016-0015$

Journal of Central Banking Theory and Practice, 2016, 2, pp. 133-155

Received: 23 February 2016; accepted: 17 March 2016

Željko Jović*

\title{
The Interaction Between FX and Credit Risk as an Example of Intersection of Monetary and Financial Stability Policy Goals - The Case of Serbia
}

\begin{abstract}
The financial system of Serbia is highly bank-centric and euroised, which is a common specific feature of financial systems in developing countries. High level of euroisation represents an adequate environment for the development of emphasized interaction of foreign exchange and credit risks; therefore, creation of the spillover mechanism of foreign exchange risk to credit risk is immanent for euroised systems. Although maintaining the stability of the dinar exchange rate is a secondary goal of the National Bank of Serbia in relation to price and financial stability as the primary goals, in terms of existence of the aforesaid spillover mechanism, maintaining stability of the dinar exchange rate represents the area where there is an interaction between the goals of monetary policy (price stability) and those of financial stability policy (maintaining and strengthening the financial system's stability). In order to explore whether the spillover mechanism of foreign exchange risk to credit risk exists in Serbia's financial system, the vector autoregressive (VAR) model is applied on data from the Serbian banking sector to quantify the impact of changes in the dinar exchange rates on the rate of nonperforming loans (NPLs); the sample was formed in the period of increased instability of the dinar exchange rate, from 31 January 2008 to 31 December 2010. As we have quantitatively confirmed the impact of increase in the dinar exchange rate on the increase of 90-120 days past due NPLs, we can conclude that the existence of expressed interaction between foreign exchange risk and credit risk in the Serbian financial system represents a paradigm of the regulator's need to achieve contemporary goals of monetary and financial
\end{abstract}


stability policy by maintaining relative stability of the dinar exchange rates. Depreciation of the local currency has inflationary pressure on price stability and simultaneously influences the achievement of financial stability goals through the spillover mechanism of foreign exchange risk to credit risk. In addition to taking systematic measures to reduce the level of euroisation and introduce the specific regulatory requirements, in order to protect banks and clients from the dinar exchange rate volatility, the regulator faces extremely important task of maintaining relative stability of the dinar exchange rate as the instrument to simultaneous achievement of goals of monetary and financial stability policies.

Keywords: FX risk, credit risk, non-performing loans, monetary policy, financial stability policy

JEL Code: E51, E58, G28, G32, G21

\section{Interactivity and (non)additivity of risk}

The entire history of development of risk assessment models is associated with the fact that it included separate observation and assessment of the most important financial risks, without considering their interactivity. In the literature, which comprehensively analyses risk assessment models, models for the assessment of credit risk are separated from models for the assessment of market and operational risks (Alexander \& Sheedy, 2004, Bessis, 2003, Jorion, 2003) and the issue of interactivity is not given special attention. Literature, which is primarily engaged in specific kind of model for credit risk assessment, does not recognize the aspect of observing the influence of other types of financial risk to credit risk (Bluhm, Overbeck \& Wagner, 2002, Caouette, Altman, Narayanan \& Nimmo, 2008, Duffie \& Singleton, 2003, Jones, Hensher, 2008). Special type of model for credit risk assessment, based on scoring and rating, allows the inclusion of a large number of variables while creating the model, but the influence of other types of financial risks is not specifically analyzed (Engelman, Hayden \& Tasche, 2003, Engelman \& Rauhmeier, 2006, Trueck \& Rachev, 2009). The interactivity of financial risks is not expressed in the literature which examines the impact of risk management and risk management models on creating value in banks (Resti \& Sironi, 2007).

Working papers that cover interactivity of risks in risk assessment models and the area of (non)additivity of risks are relatively new and therefore small in number, which adds to the attractiveness of this topic.

In their working paper from 2000, Jarrow and Turnbull devoted special attention to the interaction of credit and market risks (in this case, interest rate risk), which represents one of the works on this topic that raised greater interest in the scientific community (Jarrow \& Turnbull, 2000). The paper presents an over- 
view of previously developed models for risk assessment and concludes that in assessing credit risk, most of the models such as the structural model (Merton model, KMV and CreditMetrics model) and actuarial models (CreditRisk+) assume constant market variables (characteristic for market risk), do not include them in the model or do not generate them empirically but artificially through the model. In their work, these experts have concluded that the above mentioned models include separated observation of credit and market risk, without the possible interaction between these two risks. The authors represent their model as an example of the reduced form of the model and method for understanding the interaction between the market and credit risk, which provides the introduction of LIBOR (London Interbank Offered Rate) and assessment of its impact on the level of credit spread.

In several studies based on regression analysis of data from the United States financial market, there is quantitative evidence of the presence of correlation between interest rates on government securities, as variable in the market risk area, and credit spread, as an indicator of the level of credit risk (for more details see: Duffee, 1998 and Longstaff \& Schwartz, 1995). The analysis, which was conducted on the data in the UK, quantitatively confirmed that the interest rate is a very important factor that influences credit quality (Benito, Whitley and Young, 2001).

As a research paper under the sponsorship of the Bank for International Settlements, the analysis on a hypothetical case was introduced, which offered an integrated consideration of credit and market risk with respect to their interactivity when assessing their impact on economic value of the banks, future profitability and capital adequacy, under normal and stressful conditions (Drehmann, Sorensen, and String, 2006).

Especially important for this research is the work which examines the phenomenon of spillover of foreign exchange risk into credit risk (Božović, Urošević \& Živković, 2009). The authors claim that in developing countries, in order to protect themselves against foreign exchange risk, given that sources in foreign currency prevail in overall funding sources, banks largely grant loans in foreign currency. The depreciation of the local currency causes an increase in loan liabilities of the debtor and weakens loan repayment options, which increases credit risk. As described above, there is a spillover of foreign exchange risk into credit risk in the banking sector in developing countries.

The issue of FX induced credit risk in the banking sector of the Republic of Serbia is examined in one study on the basis of data covering December 2008 to August 
2011, with special emphasis on the possibilities and use of forward contracts in order to protect against the risk (Travica, 2012). The paper confirms the presence of a material correlation between the foreign exchange rate and the level of problem loans and reveals the little use of forward contracts as an instrument for hedging.

By using the extended vector autoregressive model, the authors attempt to quantify the interaction between market and credit risk in the banking sector in Italy (Fiori \& Iannotti, 2010).

In the Annual Report on Financial Stability, the National Bank of Serbia presents the results of macroprudential stress tests, which indicate recently that changes in dinar exchange rates are extremely important factor that influences the level of problem loans and that credit and foreign exchange risks are considered to be very significant systemic risk in the banking sector of the Republic of Serbia (Annual Report of the financial stability for the year 2012, more detailed at: www.nbs.rs).

The objective of this paper is to examine the interaction between credit risk and foreign exchange risk and to assess the extent to which foreign exchange risk can be a determinant of credit risk. Special attention will be paid to spillover effects of foreign exchange risk into credit risk.

\section{The relationship between monetary policy and financial stability}

Prior to the recent financial crisis and the recognition of the need to allocate macroprudential policy as a separate part of macroeconomic policy, the prevailing paradigm was that the preserving price stability as an objective of monetary policy was sufficient for achieving macroeconomic stability (Blanchard, Dell'Ariccia \& Mauro, 2013). However, the lessons learned in the crisis have shown that, despite the achieved price stability, the presence of serious and uncontrolled growth in property prices and credit growth may cause macroeconomic instability (International Monetary Fund - IMF, 2013). This is precisely what caused a review of the previously valid paradigm and brought to recognition the need for establishment of special type of macroeconomic policy, which will focus on financial stability issues (macroprudential policy). The objectives of monetary policy and macroprudential policy are different but complementary in the long term. Price stability as a goal of monetary policy cannot be achieved without a stable financial system, same as the stability of the financial system cannot be achieved without price stability. Monetary policy and macroprudential 
policy can be complementary, but in some cases they may be expressively divergent, which requires the development of a special framework for macroprudential policy to resolve the aforementioned conflict (IMF, 2013). Monetary policy works through mild or restrictive measures, which affect the aggregate values and this influences the movement of the business cycle by using the reference interest rate as one of the most important instruments. An example of the simultaneous achievement of the objectives of both policies is a high reference interest rate that can simultaneously influence the reduction of inflation and the reduction of credit growth. However, in certain cases, monetary policy measures can produce adverse effects on macroprudential policy - a low interest rate, which is an adequate response to low inflation, may accelerate growth of credit activity and the value of property as early indicators of entering into financial instability; considerable increase in the interest rate as a measure against inflation can attract foreign capital and cause a certain level of financial instability etc.Some studies indicate that too little attention within the transmission mechanism was devoted to the relationship between monetary policy and the perception of risk and that it is necessary to give special consideration to the impact of monetary policy on the risk-taking channel, especially in the conditions of financial liberalization and intensive financial innovation (Borio \& Zhu, 2008). Because of these and similar reasons, the need to establish independent macroprudential policy as a separate part of macroeconomic policy has been recognized over time. Therefore, we can say that monetary policy and macroprudential policy, each in their own way, through interaction and complementarity, contribute to preserving and strengthening the financial system stability.

Macroprudential policy represents a prudential tool whose main objective is to limit the systemic risk in the financial sector (IMF, 2011). The need for macroprudential policy is justified by the presence of three types of negative externalities (negative external assets) in the financial system: 1) the tendency of the financial system to amplify negative aggregate shocks, 2) macro-financial feedback mechanism that results in excessive exposure of the system to certain types of negative aggregate shocks 3) connections within the financial system, which increases the sensitivity of the system to aggregate or idiosyncratic shocks. Systemic risk is defined as a risk of disruption to financial services that is caused by an impairment of all or parts of the financial system and that has the potential to cause serious negative consequences for the real economy (IMF \& Bank for International Settlements - BIS, 2009). Macroprudential policy has three important tasks: 1) to increase the resilience of the financial system to the aggregate systemic shocks by creating a buffer that can absorb their impact and help maintain the financial system's ability to provide credit to the real economy, 2) to minimize the time dimension of risk, i.e. risks arising from procyclicality 3 ) to reduce risks arising 
from the significant interconnection between financial institutions (IMF, 2012). The time cyclicality is inherent to the financial system and manifests itself in the fact that in the growth stage (phase of expansion), there is excessive risk-taking tendency by financial institutions (expressed as credit growth, property price growth, excessive borrowing, etc.), while in the downward phase there is the reverse effect (decline in property prices, uncertainty in the market, deleveraging etc.) and significant risk aversion. Significant interconnection between financial institutions is present when risks in one financial institution could transfer to another institution and cause negative effects. Macroprudential measures that can be applied in the event of significant interconnection between financial institutions, which indicates the importance of the same system, may be e.g. higher capital requirements for systemically important institutions etc. Macroprudential measures that can be applied in the event of time cyclicality are higher capital requirement at the time of expansion, the introduction and tightening of certain ratios (LTV - Loan-to-Value, DTI - Debt-to-Income), disclosure of data about the presence of systemic risks and warning about them, etc.

With the recognition of the need for macroprudential policy, the first analysis of costs and benefits of the use of macroprudential measures was introduced (Arregui et al., 2013) to monitor the effect on GDP in the case of application of macroprudential measures. If cost of implementation of measures is denoted with $\alpha$, with $p$ representing the probability of crisis in the absence of measures and $\mathrm{p}^{*}$ being the probability of crisis in case of application of macroprudential measures, with $l$ denoting the loss in the absence of measures and $l^{*}$ being the loss in the case of application of macroprudential measures, the previous figure provides an overview of the effects of macroprudential measures applied to the level of GDP (where GDP in the absence of crisis is marked with $Y^{*}$ ). The working paper presents an analysis which indicates that the application of macroprudential measures contributes to less adverse effect of the crisis on GDP. Probability of crisis is directly proportional to growth of the loans/GDP ratio and growth in the real estate prices, which can be clearly confirmed in the case of the recent financial crisis. Macroprudential instruments can affect the aforementioned indicators (loans/GDP and real estate prices) and therefore reduce the probability of crisis $(p)$. The introduction of macroprudential measures, such as limiting certain activities and interconnectedness of the system, could influence the size of loss of GDP $(l)$ in the event of a crisis. 
Figure 1: Costs and benefits of the use of macroprudential measures

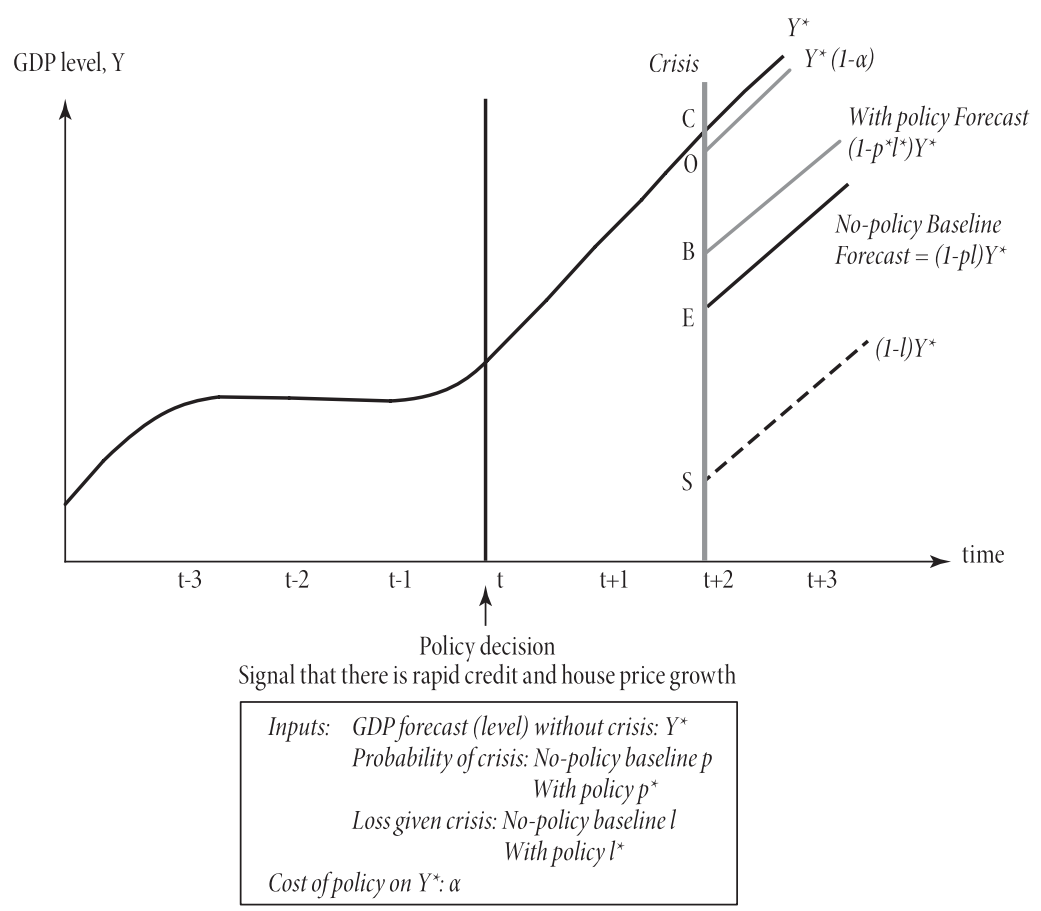

Source: Arregui et al. (2013).

The Law on the National Bank of Serbia stipulates that the primary objective of the National Bank of Serbia is to preserve price stability and, without prejudice to its primary objective, the National Bank of Serbia contributes to preserving and strengthening the stability of the financial system. Two objectives of the National Bank of Serbia (NBS) can be clearly distinguished - price stability as an objective of monetary policy and the stability of the financial system as an objective of financial stability policy (macro and micro prudential policy). Maintaining the stable dinar to euro exchange rate represents a secondary objective for the NBS, which indirectly serves primarily to the maintaining of price stability. Bearing in mind that the NBS's Financial Stability Report recognizes the dinar exchange rate as a significant systemic risk factor, it is clear that maintaining a stable dinar exchange rate is an objective that serves to preserving financial stability. Therefore, we can conclude that maintaining stability of the dinar exchange rate simultaneously affects the objectives of monetary policy as well as financial stability, that is, the maintaining of price stability and the financial system stability. 
The impact of the dinar exchange rate on financial stability in Serbia is materialized in such a way that an increase in the dinar exchange rate, in terms of high rates of euroisation, affects reducing the possibility of bank clients to regularly repay their loans and, consequently, increases the level of credit risk. This mechanism of influence is defined as the impact of the dinar exchange rate on the level of credit risk known as credit-exchange rate risk, which from the point of the financial stability report represents a systemic risk. The subject of this study is to quantify the impact of the foreign exchange rate on credit risk level on a selected sample from the banking sector of Serbia.

\section{The impact of the foreign exchange rate on credit risk - an empirical case study of Serbia}

\subsection{Defining the sample and premises for research}

Companies' portfolio from the peer which includes 5 largest banks (peer 1) from the banking sector of Serbia is chosen in order to conduct an analysis of potential impact of the foreign exchange rate on the credit risk level. The basic assumptions which were taken into account in the sample source for observation are:

- the sample includes 36-month time series (covering the period from 31 January 2008 to 31 December 2010) and as such includes the period of expressed fluctuations of the dinar exchange rate,

- the sample includes companies which obligations to a bank exceed $€$ 100000 ,

- the sample includes loans which are granted in different currencies (dinars, euros etc.) and the currency structure of portfolio is completely identical to the actual currency structure of portfolio,

- the NPL rate has not been observed according to the amount of the exposure but according to the number of clients, in order to avoid the influence of the size of clients at the NPL rate.

The average dinar exchange rate of the month has been chosen for the value of dinar exchange rate because it is the best indicator of real situation of the foreign exchange rate of the month. Analysis of the chosen sample shows that portfolio granted in euros or dinars, which are indexed to the euro currency clause, dominated the portfolio structure. Also, it is noticeable that the euro-denominated share of the portfolio was slowly decreasing but remained dominant $(79 \%-52 \%$, based on the number of clients). 
The NPL rate for the total portfolio was calculated for the chosen sample, as well as portfolio granted in euros and portfolio granted in dinars. Figure 2 shows the NPL trending over the observed period, in addition to the NPL rates shown in dinars and the NPL rates shown in euros.

Here we have a direct question whether the change of the dinar exchange rate has an impact on the NPL rate as an indicator of the level of credit risk in a bank. The figure shows that the NPL rate for the euro portfolio increased in the conditions of the increased dinar exchange rate but that is not an adequate evidence to confirm the hypothesis that the dinar exchange rate has an impact on the level of credit risk. There are several reasons why it is necessary to be cautious and not to jump to conclusion when it comes to the connection between the dinar exchange rate and the NPL rate:

- there is a possibility that the dinar exchange rate and the NPL rate were prone to increase in the observed period yet the dinar exchange rate did not have the main influence on the NPL rate, but rather both categories had factors that influenced them separately.

- the fact itself which shows that a client took a loan in euros does not mean that he/she was exposed to foreign exchange risk because it depends on the structure of its foreign currency sub-balance,

- companies that do not export very often in their dinar denominated prices covertly calculate certain dinar exchange rates (prices are covertly linked to the dinar exchange rate) so that in this way they partly amortize the effect of growth of the euro exchange rate to their obligations,

- in addition to the dinar exchange rate, many factors influence the NPL rate in banks, so there is always the question how real is the influence of change of the dinar exchange rate. 
However, based on experience, clients often point out their problems in servicing obligations imposed by changes in the dinar exchange rates, banks intuitively conclude that fluctuations in the dinar exchange rate is a possible factor of violating clients' creditworthiness and the NBS recognizes the analysis of credit and foreign exchange risks as an essential part of the analysis of credit risk of borrowers. All of that imposes the need to examine this connection in detail and to demonstrate it more concretely.

Taking into account that all clients may be exposed to oscillations of the foreign exchange rate, depending on their foreign currency sub-balance (or more precisely, what is their sensitivity to the foreign exchange rate because the purchase and selling prices in dinar may be hiding inside the connection to the euro), it is not suitable to observe portfolio granted in euros, only on the basis of the analysis of exposure to changes of the dinar exchange rate, but the overall portfolio. Therefore, the following sections examine the relationship between the exchange rate and NPL rate for the total portfolio.

\subsection{Defining a model for the assessment of impact of the foreign exchange rate on the NPL rate}

The analysis of time series which describes the NPL rate trending and the analysis of time series which describes the movement of the nominal dinar exchange rate in the period 31 January 2008 - 31 December 2010 reveals that both time series have unsteadiness level of integration 1, i.e. they have a unit root. In conditions when both time series are non-stationary and have a unit root, it is necessary to analyze whether there is cointegration of these time series (Greene, 2002, Mladenovic \& Nojković, 2015), i.e. whether these two series are harmonized in the long term. After performing the cointegration analysis between the NPL rate and the dinar exchange rate, we came to the conclusion that there is no cointegration relationship between these two time series. The aforementioned statistical result indicates that there is economic dependence between these two economic categories.

However, before concluding from the obtained results that there is not statistically and economically acknowledged dependence between the NPL rate and the foreign exchange rate, it is necessary to undertake some additional analysis. Economic logic tells us that it is unlikely that the foreign exchange rate fluctuations make an impact on the NPL rate in the same month, but rather in the periods after that (with delay). In order to move a client that repays its liabilities regularly to a client with the NPL status, 90 days or three months have to pass; for clients 
who are late up to 30 days, two months need to pass before they receive the NPL status, and so on. The economic logic itself that there is a time delay does not give us the answer to the question of exactly how late is the effect on the NPL rate. Also, it is possible that the foreign exchange rates for a number of months affect the NPL rate (e.g. the transfer of a client with little payment delay to a default client will be affected by the foreign exchange rate with a three months delay; the foreign exchange rate will affect a client that is more in delay with a two- or one-month delay etc.). It is necessary to consider both possibilities, but it is primarily significant to determine the foreign exchange rate with a delay that achieves the greatest effect on the NPL rate in time t. Let us first just compare the logarithms of the NPL rates and foreign exchange rates at different times and then we can move on to statistical analysis. Figure 3 shows the relationship between the logarithmic value of NPL rates and the logarithmic value of the foreign exchange rate at time $\mathrm{t}$ (assuming that there is

Figure 3: Ratio of relationship between the logarithmic value of NPL rates and the logarithmic value of the dinar exchange rate at time $t$

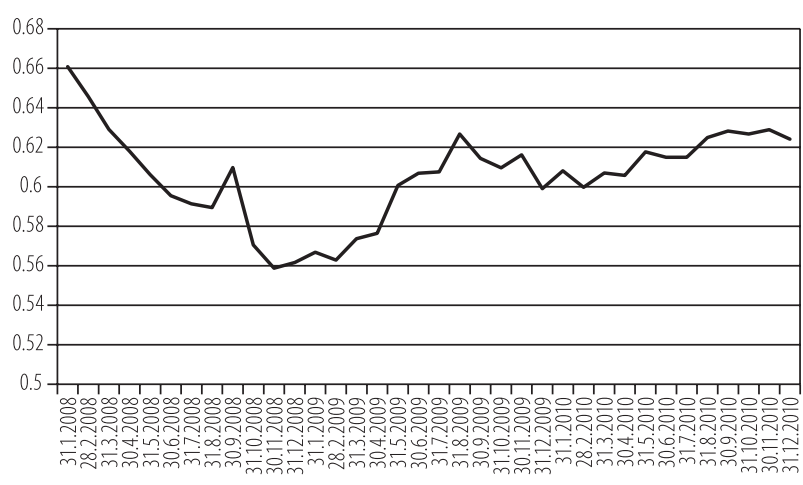

Figure 4: Ratio of relationship between the logarithmic value of NPL rates and the logarithmic value of the dinar exchange rate with one month delay

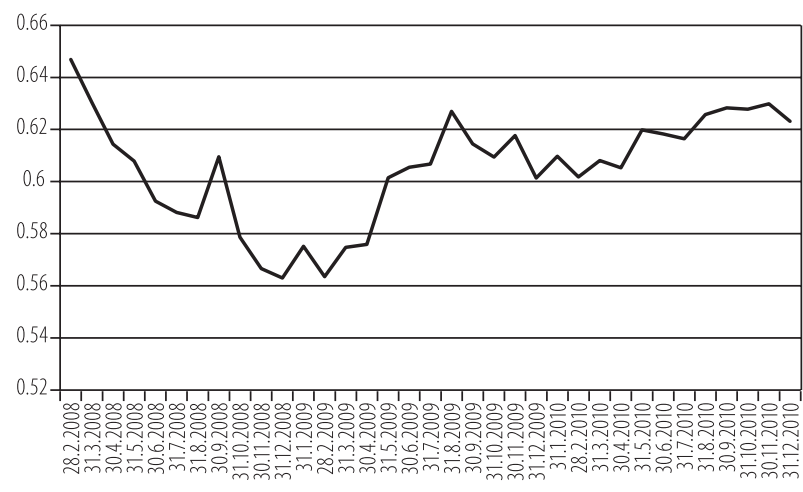
no time delay in foreign exchange rate effects). 
Figure 5: Ratio of relationship between the logarithmic value of NPL rates and the logarithmic value of the dinar exchange rate with two months delay

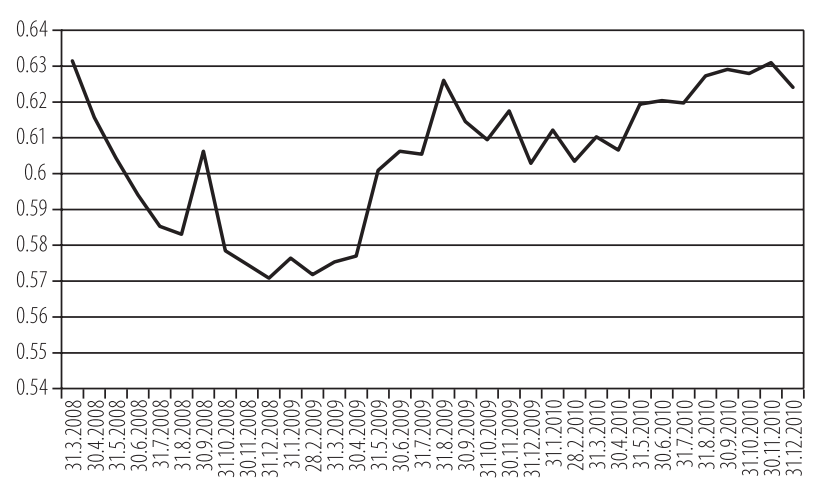

Figure 6: Ratio of relationship between the logarithmic value of NPL rates and the logarithmic value of the dinar exchange rate with three months delay

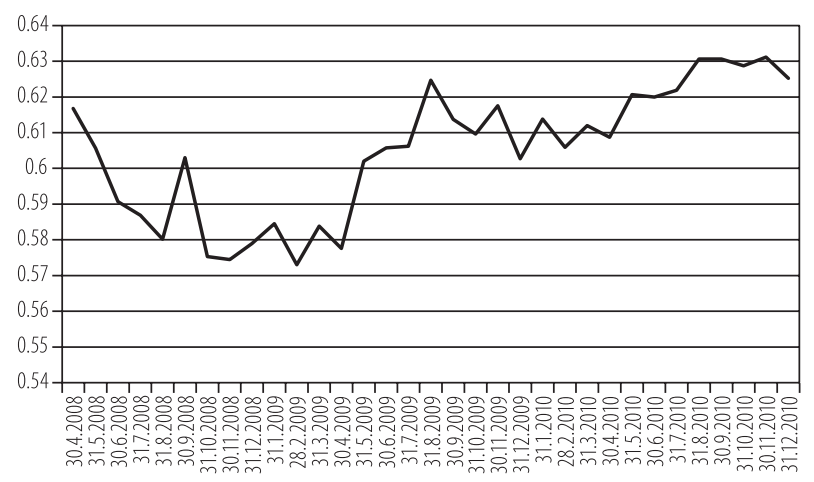

In the fourth delay of the foreign exchange rate we notice more agreement between the impact of the foreign exchange rate and the level of NPLs. Such a trend partly justifies the opinion that the foreign exchange rate with a delay of four months affects the NPL rate. However, it is necessary to quantitatively prove that there is a real connection between these categories because if we continue this, we will make artificial connection that can be statistically meaningless. However, before we move to the statistical analysis, we will look at the ratio between the NPL rate and foreign exchange rate with a delay of five months (Figure 8). 
It is noticeable that there is even more agreement in this case, as well as the existence of a specific trend in movement, i.e. this ratio is increasing over time. Of course, at this point, it is necessary to specify the delay of the foreign exchange rate with the strongest connection between the foreign exchange rate and the NPL rate. It is not possible to prove this only based on the NPL rates to foreign exchange rate ratio but it is necessary to conduct a further econometric analysis.

In case of the foreign exchange rate with the delay of one, two, three, four and five months in a row, if we look at them as a separate time series, there is a nonstationarity of the integration level 1 , i.e. the mentioned series have one unit root. On the basis of testing cointegration of these time series and time series which describes the NPL rate, we come to the following conclusion:
Figure 7: Ratio of relationship between the logarithmic value of NPL rates and the logarithmic value of the dinar exchange rate with four months delay

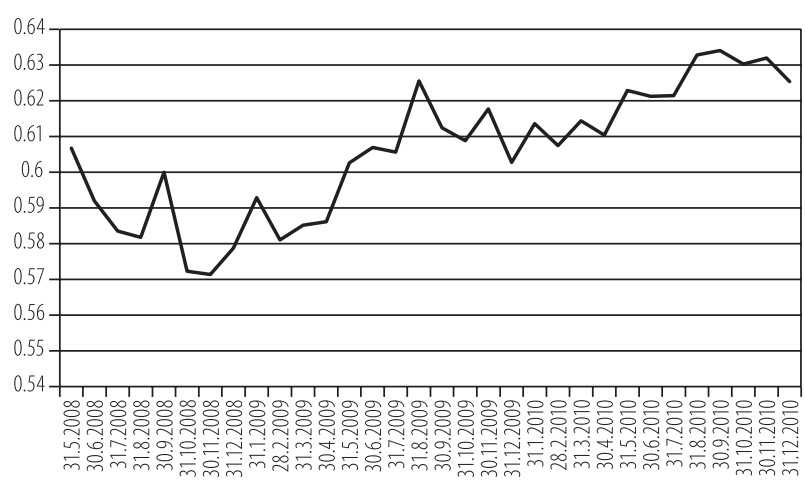

Figure 8: Ratio of relationship between the logarithmic value of NPL rates and the logarithmic value of the dinar exchange rate with five months delay

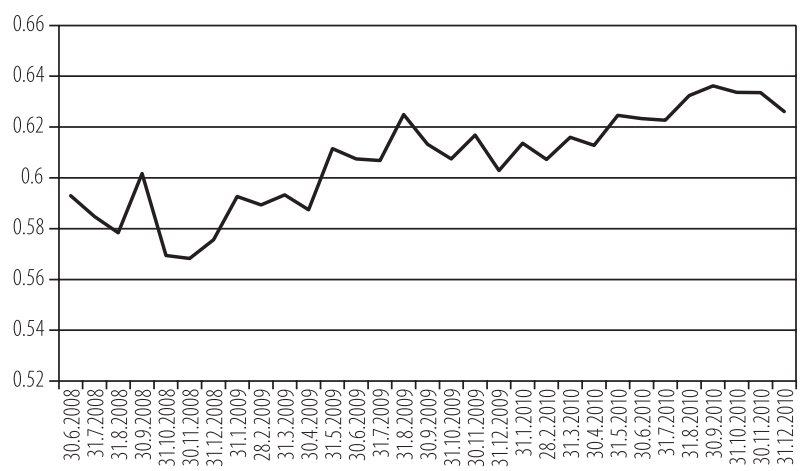


- the foreign exchange rate with a one month delay and the foreign exchange rate with two months delay (as an individual time series which are observed on the one side) and the NPL rate (which is observed on the other side) are not cointegrated,

- the foreign exchange rate with delay of three months, four months, and five months as individual time series which are observed on one side, and the NPL rate which is observed on the other side, are cointegrated.

The thing that appears as a problem is to establish which of the three time series cointegrated with the NPL rate (foreign exchange rate with three months delay, foreign exchange rate with four months delay, and foreign exchange rate with five months delay) gives the best explanation of the connection between a change of the foreign exchange rate and the impact of that change on the level of NPLs. The answer is simple - it is the time series that gives the best results when it is placed as an error correction model.

If the foreign exchange rate with three months delay and the NPL rate are taken into consideration, we have the following error correction model (Mladenović \& Nojković, 2015; Mladenović \& Nojković, 2011):

$$
\Delta \hat{Y}_{t}=-0,702070 R 3(-1)+0.397205 \Delta X(-3)
$$

$$
\bar{R}^{2}=0,50
$$

where:

$\Delta \hat{Y}_{t}$ - a change of the NPL rate between the moment $\mathrm{t}-1$ and $\mathrm{t}$, $R 3(-1)$ - a residual of the simple classical linear model between $\mathrm{Y}$ and $\mathrm{X}(-3)$ with one month delay i.e. the factor of correction in long time limit, $\Delta X(-3)$ - a change of the nominal foreign exchange rate with three months delay.

The given p-value amounts to 0.1693 , therefore we have to accept null hypothesis that the value of the regression coefficient in front of $\Delta X 3_{t}$ is equal to zero and thus we reject alternative hypothesis that $\Delta X 3_{t}$ is statistically significant for explanation of trend of the NPL rate.

If we take into account the results of error correction model which involved the foreign exchange rate with four months delay and the NPL rate, we get:

$$
\Delta \hat{Y}_{t}=-0,897047 R 4(-1)+1.051800 \Delta X(-4)
$$

$$
\bar{R}^{2}=0,54
$$


Where:

$\Delta \hat{Y}_{t}$ - a change of the NPL rate between the moment $\mathrm{t}-1$ and $\mathrm{t}$, $R 4(-1)$ - a residual of the simple classical linear model between $\mathrm{Y}$ and $\mathrm{X}(-4)$ with a one month delay i.e. the factor of correction in long time limit, $\Delta X(-4)$ - a change of the nominal foreign exchange rate with four months delay.

Additionally, we can present results of the error correction model which involved the foreign exchange rate with five months delay and the NPL rate:

$$
\begin{gathered}
\Delta \hat{Y}_{t}=-0,872586 R 5(-1)+1.035792 \Delta X(-5) \\
(0,22) \quad(0,39) \quad \bar{R}^{2}=0,31
\end{gathered}
$$

where:

$\Delta \hat{Y}_{t}$ - a change of the NPL rate between the moment $\mathrm{t}-1$ and $\mathrm{t}$, $R 5(-1)$ - a residual of the simple classical linear model between $\mathrm{Y}$ and $\mathrm{X}(-5)$ with one month delay i.e. the factor of correction in long time limit, $\Delta X(-5)$ - a change of foreign nominal exchange rate with four months delay.

On the basis of presented results, we can conclude that in case of both models (the foreign exchange rate with four months delay and the foreign exchange rate with five months delay), there is a statistically significance of the foreign exchange rate as the explanatory variables. However, having in mind that the model which includes the foreign exchange rate with four months delay has more explaining power, which is measured with the corrected coefficient of determination (Adjusted R-squared), we conclude that it is a model that best describes ratio of foreign exchange rate and NPL rate. Based on subsequent verification tests of model specifications, it is noticeable that the specification error does not exist in the model (based on RESET test). We accept that the estimated model is a reliable framework of the dependency assessment between changes in the foreign exchange rates and the NPL rate. In this way, we have confirmed that the model should not include the foreign exchange rates with other levels of delay, but that a change of the NPL rate can be explained best with a change in the foreign exchange rate with four months delay.

From an economic standpoint, it can be concluded that the NPL rate is affected by a change in the nominal foreign exchange rate with four months delay, i.e. with delay 90-120 days. From the statistical standpoint, the strength of this connection is confirmed by significance of the p-value (0.0006), which explains that it is the error that can be made, if we accept the hypothesis that there is a dependency between foreign exchange rate and NPL rate of $0.06 \%$ (which is below any 
materiality thresholds). An increase in the foreign exchange rate affects the NPL rate, but it is necessary to be cautious in the interpretation of results of the model because the value of regression coefficient of 1.051800 does not mean the change of the NPL rate due to change in the exchange rate for 1 euro (which would be accurate if the basic series are being observed), but in the role of the dependent variable is the change of NPL rate and in role of independent variables is the change of nominal euro exchange rate. In this case, the aforementioned regression coefficient explains how much the NPL rate changed in case when the foreign exchange rate changes.

Approximately 54\% of the variations in NPL rate trending can be explained through changes in the foreign exchange rate, which means that in addition to the foreign exchange rate, there is a specific number of the other variables that explain the change in the level of the bank's credit risk in the observed period. However, they are not the subject of this paper and they will not be further considered. Further tests will be conducted ( $Q$ test and JB test), as well as the analysis on the basis of the application of the vector autoregressive model, before the final conclusion on the existence of connection between the NPL rate and the euro exchange rate with four months delay is drawn.

Application of the Ljung-Box test (Q test) on residuals obtained from the error correction model that considers the ratio between the NPL rates and the euro exchange rate with four months delay in the program package Eviews confirms that there are no registered deviations that would confirm the existence of autocorrelation.

Figure 9: $Q$ test results - report from Eviews

\begin{tabular}{|c|c|c|c|c|c|c|c|c|}
\hline \multicolumn{2}{|c|}{ Autocorrelation } & \multicolumn{3}{|c|}{ Partial Correlation } & \multirow{2}{*}{$\frac{\text { AC }}{-0.066}$} & \multirow{2}{*}{$\begin{array}{c}\text { PAC } \\
-0.066\end{array}$} & \multirow{2}{*}{$\frac{\text { Q-Stat }}{0.1494}$} & \multirow{2}{*}{$\frac{\text { Prob }}{0.699}$} \\
\hline 1 प & 1 & 4 & 1 & 1 & & & & \\
\hline 1 & I & 10 & I & 2 & -0.149 & -0.154 & 0.9313 & 0.628 \\
\hline 1 & 1 & 4 & 1 & 3 & -0.045 & -0.069 & 1.0067 & 0.800 \\
\hline$]$ & । & 1 & I & 4 & 0.054 & 0.023 & 1.1175 & 0.891 \\
\hline 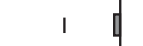 & I & 1 & 1 & 5 & -0.028 & -0.041 & 1.1491 & 0.950 \\
\hline t & । & 1 & I & 6 & -0.081 & -0.080 & 1.4145 & 0.965 \\
\hline 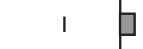 & 1 & 1 & 1 & 7 & 0.093 & 0.077 & 1.7859 & 0.971 \\
\hline 5 & । & I & I & 8 & 0.064 & 0.051 & 1.9687 & 0.982 \\
\hline 1 & 1 & 1 & I & 9 & 0.022 & 0.053 & 1.9919 & 0.992 \\
\hline 1 & I & 1 & 1 & 10 & -0.039 & -0.001 & 2.0648 & 0.996 \\
\hline । & । & 1 & I & 11 & 0.025 & 0.032 & 2.0975 & 0.998 \\
\hline । & 1 & 1 & I & 12 & 0.107 & 0.112 & 2.7130 & 0.997 \\
\hline 14 & 1 & 다 & 1 & 13 & -0.139 & -0.108 & 3.8042 & 0.993 \\
\hline 1 & 1 & 1 & 1 & 14 & 0.091 & 0.118 & 4.3012 & 0.993 \\
\hline $1 \square$ & 1 & 14 & I & 15 & -0.153 & -0.185 & 5.7888 & 0.983 \\
\hline 1 & 1 & $1 \quad 4$ & 1 & 16 & -0.044 & -0.073 & 5.9209 & 0.989 \\
\hline
\end{tabular}


Also, apllication of the Jarque-Bera test (JB test) for the evaluation of normality confirms that null hypothesis on the existence of normality in distribution of residuals can be accepted.
Figure 10. JB test results - report from Eview

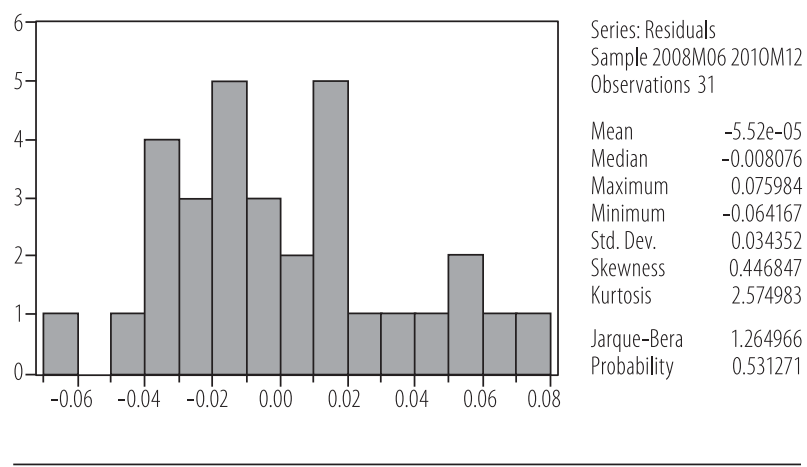

\subsection{The analysis of the connection between the NPL rate and the euro exchange rate on the basis of VAR model application}

Having in mind that the previous analysis showed the existence of integration between the logarithmic value of the NPL rate (y) and the logarithmic value of the middle dinar exchange rate with the four months delay $(\mathrm{x}(-4))$, these two time series can be included in the evaluation on the basis of application of the vector regressive model (VAR model).

On the basis of the sequential test of selecting the optimal number of delays, tests of information criteria and test of normality and autocorrelation in each of the first six delays, we come to conclusion that the optimal number of delays is three.

If on the basis of the obtained results as the optimal delay in the VAR model we choose the third delay and use the Granger causality testing with the significance level of $5 \%$, we find that there is one-sided causation (the middle exchange rate affects the NPL rate but the NPL rate does not affect the middle exchange rate).

Table 1: The analysis of causality between foreign exchange rate and NPL rate in the third delay

\begin{tabular}{lr}
\hline Granger causality testing & p-value \\
\hline Impact of the foreign exchange rate on the NPL rate of companies & 0.00 \\
\hline Impact of the NPL rate of companies on the foreign exchange rate & 0.24 \\
\hline Normality and autocorrelation test & p-value \\
\hline Doornik-Hansen test for normality & 0.54 \\
\hline Portmanteau test of autocorrelation - Q(12)/corrected Q(12) & $0.39 / 0.08$ \\
\hline
\end{tabular}


Also, the Granger causality testing on a model with a smaller number of delays (e.g. 1), which has also been confirmed as significant on the basis of sequential testing and tests of information criteria, confirmed the existence of unilateral causality (the middle exchange rate affects the NPL rate but the NPL rate does not affect the middle exchange rate). These results show that there is simultaneity between these two variables.

After the confirmation, using the causality test which shows that there is a unilateral causality in terms of the influence of foreign exchange rate on the level of credit risk, measured by the NPL rate, we can conduct an analysis of variance decomposition in order to determine the strength of this influence, as well as the impulse response function in order to determine direction and intensity of the influence. On the basis of analysis of variance decomposition in a defined order of influence in the analysis, in the way that foreign exchange rate influences the NPL rate (Table 2, a)), we conclude that, in the given sample and defined observation period, after the first quarter, approximately $9.4 \%$ of the changes in the NPL rate can be explained by the influence of the foreign exchange rate, as well as that after six months, about $60.3 \%$ of the changes in the NPL rate can be explained by the changing foreign exchange rate. The result is stable even in the case when the Cholesky ordering has been changed (Table 2, b)).

Table 2: The analysis of variance decomposition in the foreign exchange rate to NPL rate ratios

a) Random error variance decomposition in trend of the NPL rate of companies (Cholesky ordering: foreign exchange rate - NPL rate)

\begin{tabular}{lcc}
\hline Period & NPL rate of the companies & Foreign exchange rate \\
\hline First quarter & 90.6 & 9.4 \\
\hline Second quarter & 39.7 & 60.3 \\
\hline
\end{tabular}

b) Random error variance decomposition in trend of the NPL rate of companies (Cholesky ordering: NPL rate - foreign exchange rate)

\begin{tabular}{lcc}
\hline Period & NPL rate of the companies & Foreign exchange rate \\
\hline First quarter & 91.7 & 8.3 \\
\hline Second quarter & 44.9 & 55.1 \\
\hline
\end{tabular}

Based on the analysis of the impulse response function (Figure 11) during the one-time shock of one standard deviation, in terms of increase in the foreign exchange rate, it comes to increase in NPL rate and the effect of increase in NPL cumulated increases. These results undoubtedly show the exceptional importance of the foreign exchange rate in explaining changes in the NPL rates in the selected sample in the period 31 January 2008 - 31 December 2010, when the foreign exchange rate notably fluctuated. 
Figure 11: Analysis of the impulse response function - report from Eviews

Accumulated Response to Cholesky One S. D. Innovations
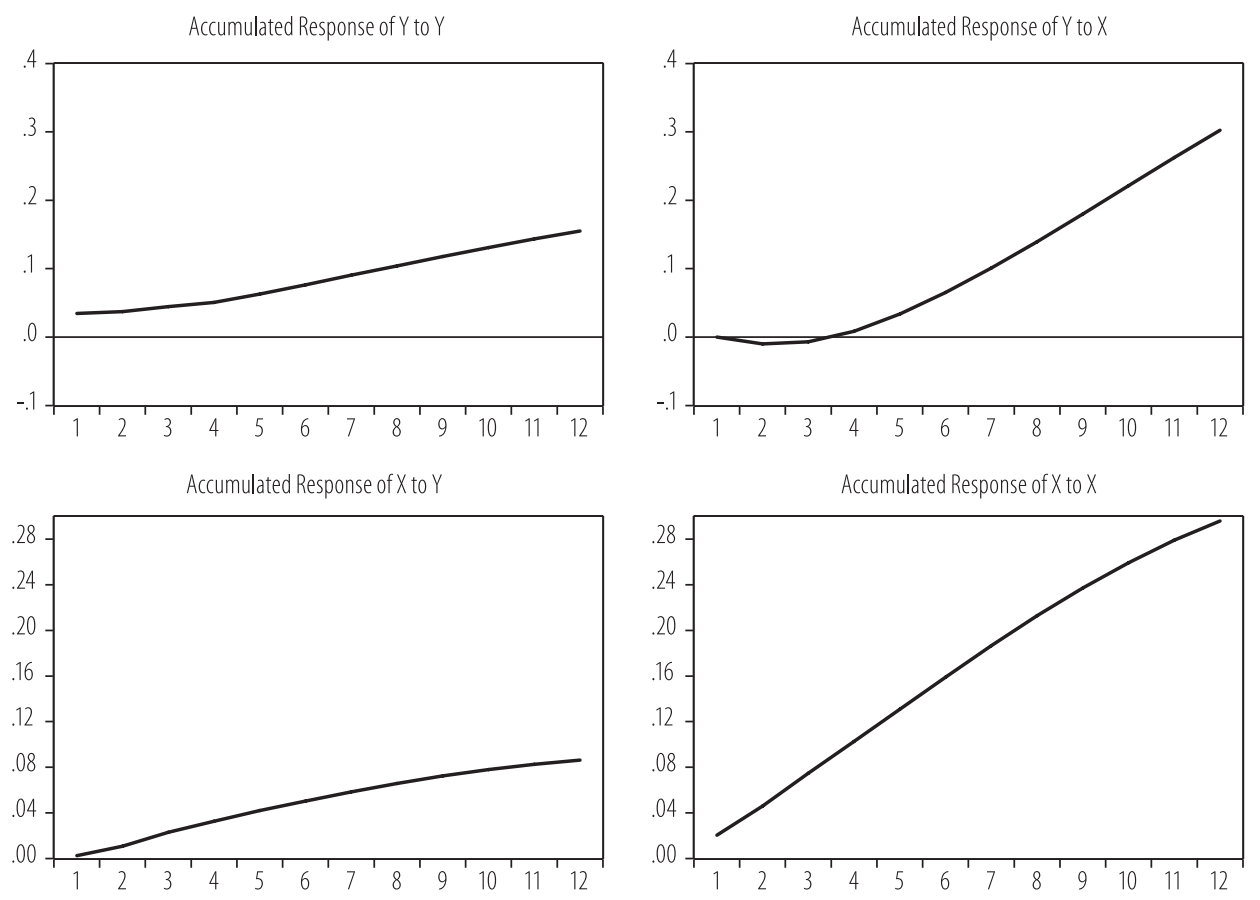

\subsection{Setting the final model of impact of the euro exchange rate on the NPL rate}

After the evidence on the absence of simultaneity, unilateral causality and the optimal number of delays, we can set the final model with error correction.

Before setting the final model which would explain the impact of foreign exchange rate on NPL rate, in order to set the model delicately, we have included in the model artificial variable (with label SER01) which will eliminate the fracture that exists in trend of NPL rate. The NPL rate as a measure of credit risk level is sensitive to a noticeable growth of assets, therefore in the high growth of assets (which exists in some parts of the time series), even if the NPL is in the absolute amount of growth, the NPL rate as a relative indicator may decrease and thus 
falsely indicate that the level of credit risk has decreased. In order to avoid this trap and improve the quality of results, we can introduce an artificial variable which will have a value 1 , if the asset growth rate is higher than the rate of NPL growth and the value 0 otherwise.

$$
\Delta \hat{Y}_{t}=-0,742123 R 4(-1)+1,104537 \Delta X(-4)-0,025246 \text { SER } 01
$$

This model has firm specifications. All parameters that were included are statistically significant. Adjusted coefficient of determination is approximately $63 \%$. Test for autocorrelation (Q test) and test for normality (JB test) show that there is no autocorrelation and that there is normality in the distribution of residuals.

Based on these results, we can conclude that on the selected sample, which includes the period of instability of dinar exchange rate from 31 January 2008 to 31 December 2010, increases in the dinar exchange rate with the delay 90-120 days affects the increase of NPL rate of the companies.

\section{Summary}

The financial system of Serbia is characterized by a high level of euroisation which, in this case, is the due to the fact that the banking sector, as the most substantive part of the financial system, is highly euroized. Most of the banks in Serbia are local banks with majority foreign capital whose sources mostly consist of funds raised outside of the country and expressed in foreign currency, primarily in euros. The largest part of funding sources refers to funds received from parent banks or other foreign sources (credit lines and similar). Saving in local banks is mostly in foreign currencies (mainly in Euros), due to continued aversion of the local population towards saving in local currency. In order to ensure adequate protection from foreign exchange risk and against the backdrop of absence of full confidence in dinar loans, most of these banks grant their loans in euros or in dinars with the currency clause linked to the euro. It specifies that, regardless of whether they are in a domestic or foreign ownership, loans granted in euros or indexed with the euro clause are dominant in portfolios of domestic banks.

The previous result obtained on the basis of data from companies' portfolio in the period 31 January 2008 - 31 December 2010, when the dinar exchange rate was highly unstable, shows that the increase in foreign exchange rate with four months delay affected an increase in the NPL rate of companies. This result confirms that in the conditions of a highly euroised financial system, the system itself 
creates the spillover mechanism of foreign exchange risk into credit risk. Each expressed instability of the euro foreign exchange rate, as the dominant foreign currency in the country, in addition to their channels of influence on prices, has great effects on creditworthiness of the real sector and consequently contributes to an increase of credit risk in the banking sector, thus giving additional tasks to regulators in the context of maintaining and strengthening financial stability. In such circumstances, maintaining stability of the dinar exchange rate is not just a secondary goal for the purpose of maintaining price stability, but it is an extremely important task in controlling systemic risk and maintaining stability of the financial system. Maintaining stability of the dinar exchange rate is the point where goals of monetary policy, which are responsible for maintaining price stability, and goals of financial stability policy intersect to ensure the maintaining and strengthening of the financial system.

Periods of expressed instability of the foreign exchange rate, such as the period chosen for analysis in this study, represent a sample case in which the spillover mechanism of foreign exchange risk to credit risk is manifested in highly euroised economies and where the cooperation between monetary policy and financial stability policy is highly needed. In addition to taking systematic measures in order to reduce euroisation and introduce additional regulatory measures which are used in order to make banks seek more cautious approach when extending loans to currency-sensitive clients, the essential task for the central bank is also to maintain relative stability of the dinar exchange rate. The secondary objective of the central bank, such as maintaining stability of the dinar exchange rate, becomes a scope where the achievement of the goals of monetary policy and financial stability policy is simultaneously affected. 


\section{Literature}

1. Alexander, C. and Sheedy, E. (2004). The Profesional Risk Managers' Handbook, Professional Risk Managers International Association.

2. Arregui et al. (2013). Evaluating the Net Benefits of Macroprudential Policy: A Cookbook, IMF Working Paper No 167.

3. Benito, A., Whitley, J. and Young, G. (2001). Analysing Corporate and Household Sector Balance Sheets, Bank of England, Financial Stability Review, December.

4. Bessis, J. (2003). Risk Management in Banking, John Wiley\&Sons.

5. Blanchard, O., Dell'Ariccia, G. and Mauro, P. (2013). Rethinking Macro Policy II: Getting Granular, IMF Staff Discussion Note 13/03 (Washington, IMF).

6. Bluhm, C., Overbeck, L., Wagner, C. (2002). „An Introduction to Credit Risk Modeling", Chapman\&Hall.

7. Borio, C. and Zhu, H. (2008). Capital regulation, risk-taking and monetary policy: a missing link in the transmission mechanism?, BIS Paper No 268.

8. Božović, M., Urošević, B., Živković, B. (2009). On the Spillover of ExchangeRate Risk Into Default Risk, Economic Annals, Volume LIV, No. 183.

9. Caouette, J.B., Altman, E.I., Narayanan, R., Nimmo, R.W.J. (2008). „Managing Credit Risk“. John Wiley\&Sons.

10. Drehmann, M., Borio, C. and Tsatsaronis, K. (2012). Characterising the financial cycle: don't lose sight of the medium term!, BIS Paper No 380.

11. Duffee, G.R. (1998). The relationship between treasury yields and corporate bond yield spreads, Journal of Finance 53 (6).

12. Duffie, D., Singleton, K.J. (2003). „Credit Risk Pricing, Measurement and Management", Princeton University Press.

13. Engelman, B., Hayden, E., Tasche, D. (2003). Measuring the Discriminative Power of Rating Sistem, Deutche Bundesbank.

14. Engelman, B., Rauhmeier, R. (2006). Basel II Risk Parameters: Estimation, Validation and Stress Testing, Springer, Berlin.

15. Fiori, R., Iannotti, S. (2010) On the interaction between market and credit risk: a factor-augmented vector autoregressive (FAVAR) approach, Banca D'Italia, No 779.

16. Greene, W.H. (2002). „Econometric Analysis“, Prentice Hall.

17. IMF (2011). Macroprudential Policy: An Organizing Framework (Washington).

18. IMF (2012). Key aspects of macroprudential policy.

19. IMF (2013). Interaction of monetary and macroprudential policies. 
20. IMF, Financial Stability Board and BIS (2009). Guidance to Assess the Systemic Importance of Financial Institutions, Markets and Instruments: Initial Considerations.

21. Jarrow, R.A., Turnbull, S.M. (2000). The Intersection of Market and Credit Risk, Jurnal of Banking and Finance 24.

22. Jones, S., Hensher, D.A. (2008). „Advances in Credit Risk Modeling and Corporate Bankruptcy Prediction", Cambridge University Press.

23. Jorion, P. (2003). „Financial Risk Manager Handbook“, John Wiley\&Sons.

24. Longstaff, F.A., Schwartz, E.S. (1995). A simple approach to valuing risky fixed and floating rate debt, Journal of Finance 50.

25. Mladenović, Z., Nojković, A. (2011). Analiza vremenskih serija: Prmeri iz srpske privrede, Ekonomski fakultet u Beogradu.

26. Mladenović, Z., Nojković, A. (2015). Primenjena analiza vremenskih serija, Ekonomski fakultet u Beogradu.

27. Resti, A., Sironi, A. (2007). Risk management and shareholders' Value in Banking, John Wiley\&Sons.

28. Travica, M. (2012). Forward as a possible solution for currency induced credit risk identified in Non-performing loans-Foreign exchange rate regression model, London School.

29. Trueck, S., Rachev, S.T. (2009). Rating Based Modeling of Credit Risk, Academic Press Advanced Finance Series.

www.bis.org www.imf.org

www.nbs.rs 